International

Journal of

Sudan Research

V8, N2

2018

\title{
SIGNIFICANT BIOACTIVE COMPOUNDS IN CRUDE METHANOL EXTRACTS AND THEIR FRACTIONS OF ACACIA SEYAL GUM
}

\section{Ahmed A.M. Elnour ${ }^{1}$, Mohamed E.S. Mirghani* 1, 3 , Nasreldin A. Kabbashi ${ }^{1}$ and Mohamed Z. Alam ${ }^{1}$}

'Bioenvironmental Engineering Research Centre (BERC), Biotechnology Engineering, Kulliyyah (Faculty) of Engineering, International Islamic University, Malaysia (IIUM),

P. O. Box 10, Gombak. 50728 Kuala Lumpur, Malaysia Email: elwathig@iium.edu.my

${ }^{3}$ International Institute for Halal Research and Training (INHART), International Islamic University, Malaysia (IIUM),

P. O. Box 10, Gombak 50728, Kuala Lumpur, Malaysia

\section{Khalid H. Musa²}

2Department of Food Science and Human Nutrition College of Agriculture and Veterinary Medicine Qassim University,

Kingdom of Saudi Arabia 


\section{ABSTRACT}

This chapter investigated the bioactive compounds (BC) of crude methanol extract (CME) and the soluble fractions of chloroform (CHF), hexane (HF), acetone (AF) and methanol (MF) of raw Acacia seyal gum (ASG) and commercial Prebio-T (PTC), respectively. The CME and its different soluble fractions were analysed and evaluated for their potential $B C$ by using Raman Spectroscopy techniques. The findings presented many comprehensive variation rules of chemical components provided by the Raman spectrum. The identification process with the Raman spectra (RS) macroscopic fingerprint characters spectroscopy provided the details on gums and their extracts, chemical constituents, as well as the comparison of the differences of the components among the fractions. The results indicated that there are three Raman spectra of the enriched extracts obtained, and a comparison was made for the effective peaks against that of raw material gum (standard). The spectra of both raw gum samples (ASG and PTC) showed three major peaks at the approximated similar range of 2930,1354 and $636 \mathrm{~cm}^{-1}$; whereas the spectra of MCE, MF and AF showed the same bands at about 1903 to $1373 \mathrm{~cm}^{-1}$. However, the MF spectrum showed two different bands at 805 and $572 \mathrm{~cm}^{-1}$. The findings showed that methanol crude extraction (CME) was found to be more effective than AF fractions in all the assays mentioned. Based on this study, the bioactivity of CME and its rich fractions are considered very promising and beneficial for using Acacia seyal gum in food processing, medicine and pharmaceutical industries. In addition, the fingerprint peaks absorbance of other fractions might suggest some of the bioactive compound(s) of chloroform, hexane and methanol crude/fractions phytochemicals from Acacia seyal gum such as carotenoids (astaxanthin) and indolic alkaloids; phenolic compounds such as ferulic acid, $p$-coumaric acid, caffeic acid and sinapic acid. Therefore, Raman spectroscopy is considered an effective tool for bioactive compounds identification.

Keywords: Antioxidants; Extraction; Gum Arabic; Acacia senegal; Phenolic compounds and Raman Spectroscopy

\section{INTRODUCTION}

Plants are the energy source for the animal kingdom and they provide benefits through the inhibition of specific diseases and illnesses, which are considered as exhibiting favourable performance in health care. In either plant or animal cells, reactive oxygen species (ROS) in the form of superoxide anion $\left(\mathrm{O}_{2}^{--}\right)$, hydrogen peroxide $\left(\mathrm{H}_{2} \mathrm{O}_{2}\right)$, hydroxyl radicals $\left(\mathrm{OH}^{\circ}\right)$ and singlet oxygen $\left(\mathrm{O}_{2}^{1}\right)$ have damaging effects on cells (Dasgupta and De, 2007; Liao et al., 2016; Mohades, 2017; J.Y. Wang et al., 2016). The oxidation process can be considered one of the most important routes in the production of free radicals in the living system, including food and drugs. Antioxidants are substances that play a role of significantly delaying or reducing the effects of substrate oxidation when present in low concentrations (Mannino, 2017). Antioxidants prevent the body from damage of oxidation reactions by reacting with other ROS and free radicals within the body, thus hindering the oxidation process (Elnour et al. 2018). Hence, the prevention of diseases associated with free radicals can be carried out by antioxidant therapy, which has been gaining significant importance. The protection against the ROS-damaging effect is feasible through antioxidant compounds that are present in many plants. The common human diseases, directly or indirectly, associated with ROS are cancer, cardiovascular diseases, inflammation, diabetes, degenerative diseases, anaemia, ischemia and ageing (Luo, 2017). The medicinal market has been receiving many extract products of medicinal materials in recent years. Concentrated extract products have been enhancing their curative effect as well as providing convenience in terms of packaging, transportation and product freight (Görög, 2015; Patel, 2009). It appears that the adoption of medicinal materials in the form of extracts has been quite extensive to a very great extent. Nevertheless, the emerging of low-quality products and counterfeits also follows the increasing trends that have 
developed in the medicinal market. Contemporarily, the main identification method used for analysing the quality of products is by utilising the chromatography technique through the content examination of ascertaining chemical constituents in the tested sample. It is widely known that hundreds of components comprise one medicinal material available in the market, and through the mutual effects of those many ingredients, curative effects can be produced. Thus, a content limitation over the specific components does not necessarily reflect the real quality of the herbal medicines. Therefore, a method for efficiently and instantly analysing the whole constituents of the materials and entirely monitoring and reflecting their corresponding extract products is required (Gill, 2014).

Raman spectroscopy is one of the most frequently used methods in identifying chemical substances and elucidating compound structures, and many countries utilise it as a requisite method in identifying medicines for pharmacopeia. Raman spectroscopy has actually a suitable application in assessing the quality of GA, which is used mainly to determine rheology and emulsifying stability (Niu et al., 2016), as well as to discriminate the GA botanical location, type and age of the tree (Wang et al. 2014). Thus, Raman is an extremely effective tool for characterisation.

Recently, Raman spectroscopy has been efficiently applied to estimate the antioxidant capacity of various foods (Wu et al., 2017; Wu et al., 2016). Raman spectroscopy depends on scattering, which is termed "an inelastic scattering of the incident light from a sample and the frequency shift by the energy of its characteristic molecular vibrations"(Wu et al., 2016; Xin et al., 2014). The different energy at the scattering time is assigned to the chemical bonds interactions present in the photon and the samples. Thus, the combination of these two different techniques can provide comprehensive information about the chemical compositions of Gum Arabic (GA) and its different extracts.

The Acacia seyal gum (ASG) (variety seyal Del.), known as Talha in various countries such as Niger, Chad, Senegal, Nigeria, and especially Sudan, is a notable traditional medicine for the treatment of common diseases, such as diarrhoea,anti-inflammatory ulcers and so forth (Elnour et al., 2018; Khalid et al. 2012). It has been reported that the active components in ASG involved nonviscous soluble fibres with high dietary value, and also minerals such as potassium, magnesium, calcium as well as antioxidants (Mirghania et al., 2018). Thus, GA is beneficial as a source of bioactive compounds.

The plant of ASG (Family: Leguminosae) is the main source of GA; the leaves, gum and bark are used in phototherapy for haemorrhage, colds, diarrhoea, gastrointestinal disorders, jaundice, biliary diseases, syphilis, headaches and as emollient, astringent, and for burns and ophthalmic purposes (El Amin, 1990). The examination of GA showed that the substance is acceptable for human daily intake by the Joint FAO/WHO Expert Committee on Food Additives since 1969 (Musa, 2015). However, the Sudanese people of Western Sudan have been consuming it without any dosage restriction. It is known to be indigestible by both humans and animals, inaccessible for intestinal degradation, but fermentable to short-chain fatty acids in the colon, resulting in the possibility of a wide range of health benefits (Phillips, 2011a). One of the benefits is the prebiotic effect (Phillips, 2011b), where a four-week supplementation with GA (10 g/day) led to significant increases in Bifidobacterium, Lactobacteria 
and Bacteroides (Calame et al. 2008). Other effects include a reduction in plasma cholesterol level in animals and humans (Sharma, 1985), anticarcinogenic effect (Nasir et al., 2010) as well as cardiac toxicity and hepatotoxicity protection (Ali, 2003). Therefore, GA can possess a multibiological function.

In addition, it has been proposed, with further studies and confirmation required, that GA also relieves chronic renal failure effects in humans (Ali, 2010; Glover et al. 2009). Therefore, the indication to use GA in food manufacturing, cosmetic and medicine trade can be seen as beneficial from the point of view of modern pharmacological research.Consequently, many researchers are attracted to study GA since some new insights on the effective functions and constituents have been acquired. In this study, the comprehensive variation rules and the main components of ASG chemical constituents and its extracts were addressed through the application of Raman spectroscopy.

Raman spectroscopy has not been applied in the prediction of antioxidant activity and phenolic compounds of Acacia seyal gum. Therefore, the development of an accurate, rapid and feasible analysis method that integrally reflects the inherent qualities of medicinal materials and their corresponding extracts is required. This should involve the crude methanol extract (CME) antioxidant capacities and their fractions from ASG natural exudate and commercial products of PTCusing free radical scavenging.

\section{MATERIALS AND METHODS}

\section{Plant Materials}

Acacia seyal gum tree and gum samples (Figure 1) were collected in November 2015; the acacia gum (AG) nodules were collected from the Blue Nile State of Sudan. After the collection, profound experts from the Sudanese Ministry of Forestry and Agriculture examined the samples of AG. This was done to ensure that all the samples were identified properly and cleaned from plant bark parts and sand. To ensure the homogeneity of the samples, a random selection of nodules was ground and made into a mechanical powder by using a USA standard testing sieve (Fisher Company) with a $1.40 \mathrm{~mm}(0.0555$ inches) mesh size. For the ASG, a commercial sample called Prebio T (PTC) was obtained from Perfect Life Food Containing Homogenized Ingredients Manufacturing Company in the United Arab Emirates. Extract preparation and the solvent-solvent partitioning process are presented in Figure 2.

\section{Raman Spectroscopy}

In this chapter, Raman spectroscopy was performed by using a Renishaw System-1000 spectrometer (Wotton-Under-Edge, UK), as presented in Figure 3a \& b, respectively. The instrument is equipped with a diode laser with a laser wavelength of $785 \mathrm{~nm}$ and an output power of $50 \mathrm{~mW}$. Laser intensity on the sample could be modified up to ca. $5 \mathrm{~mW}$, by using a set of neutral density filters. While taking possible sample inhomogeneity into consideration, for each sample, at least three Raman spectra were recorded by using the $50 \times$ objective lens, allowing for a spectral footprint of ca. $2 \mathrm{~m}$. All spectra were recorded between 400 and $3200 \mathrm{~cm}^{-1}$ for at least five accumulations of the 30 s. 


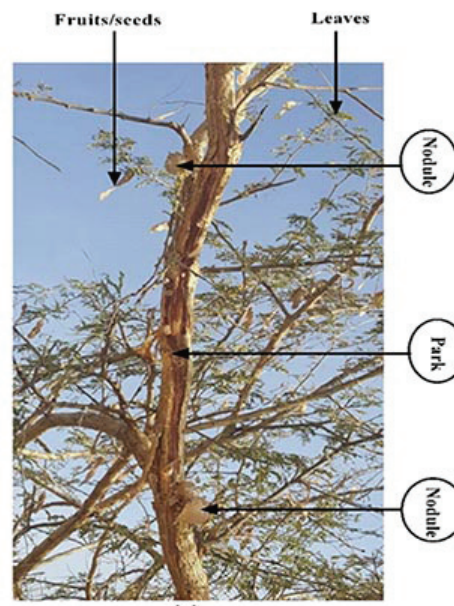

(a)

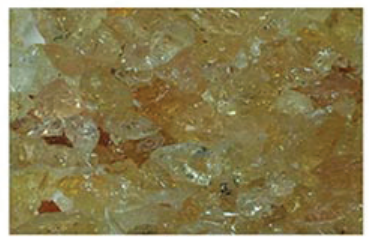

(c)

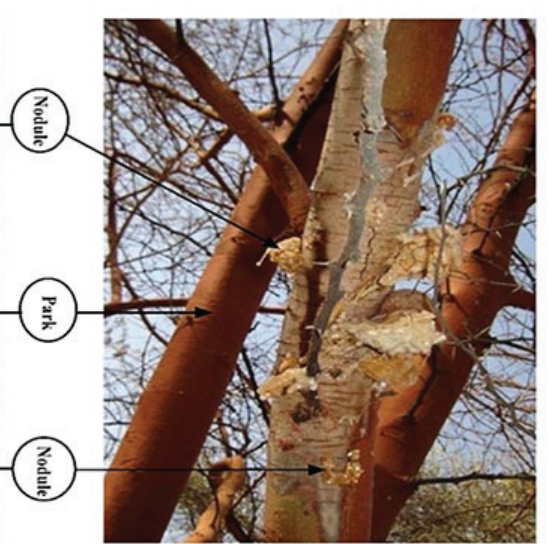

(b)

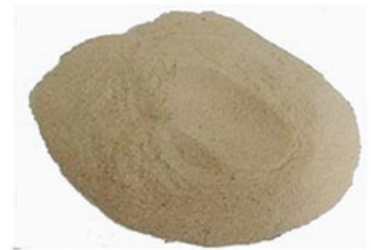

(d)

FIGURE 1(a) Shows the Acacia sengal tree (for comparison); (b) Acacia seyal tree; (c) Acacia seyal gum; and (d) PTC (Acacia seyal commercial gum).

\section{Grourd ASG/Preb in-T.Materials}

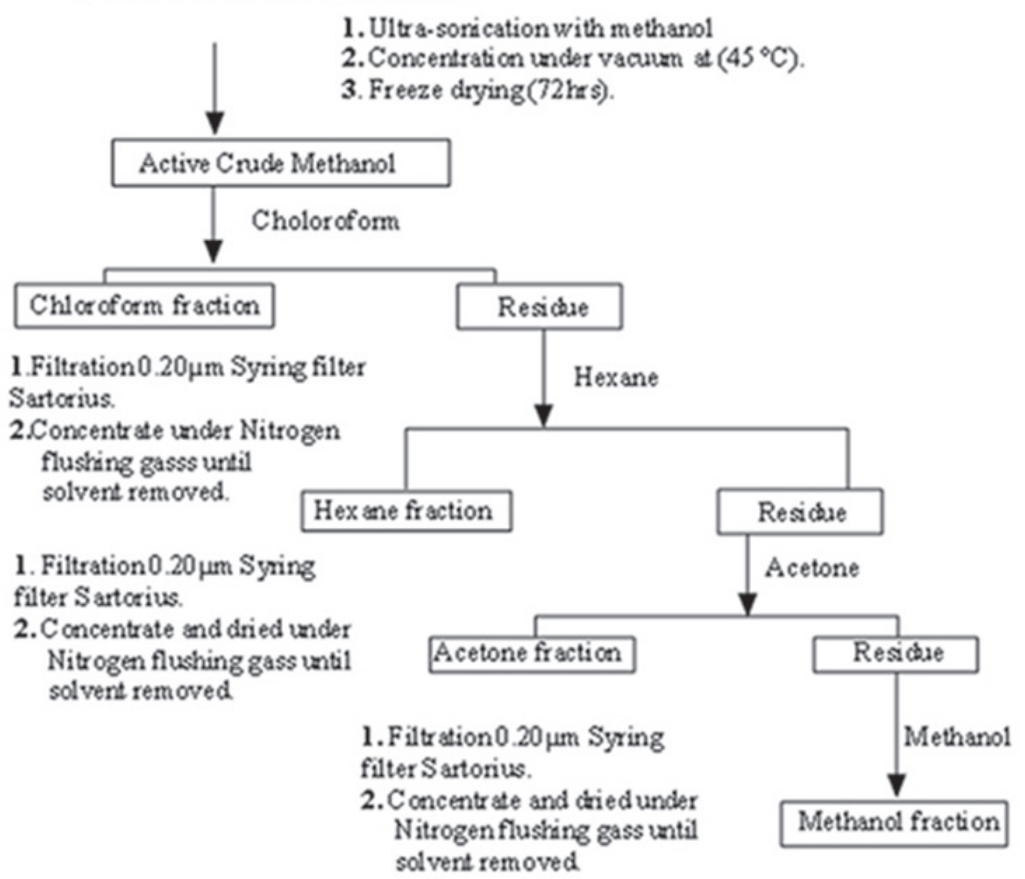

FIGURE 2 Schematic flow representation of the Kupchan solvent-solvent partitioning of a methanolic crude extract of Acacia seyal gum (ASG) and PTC crude methanol and its fractions. Procedure modified by using gum arabic branch methanol crude extract. 


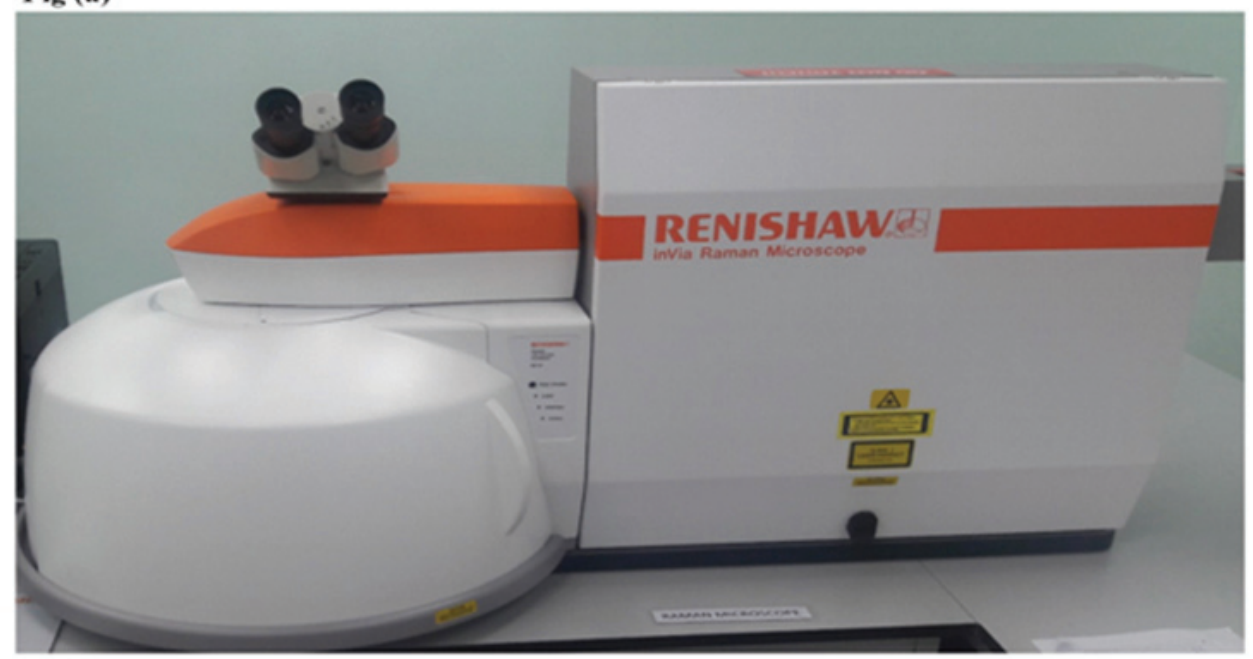

Fig (b)

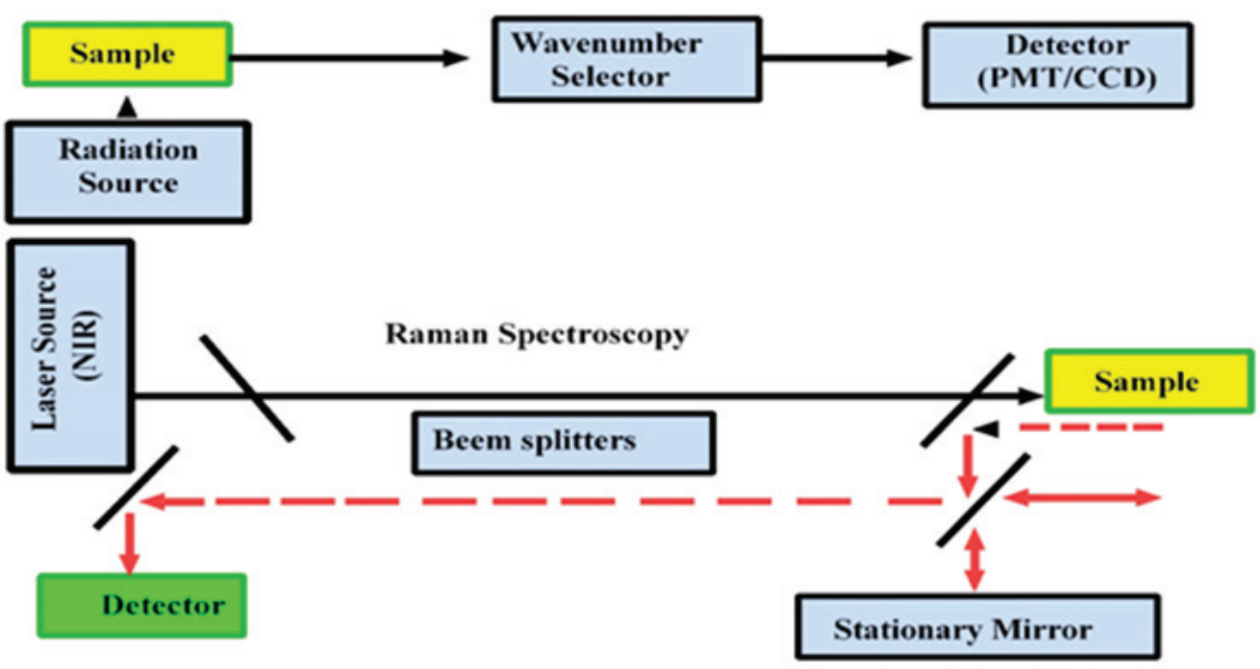

FIGURE (3a \& b) Dispersive Raman spectroscopy diagram Source: from (Rostron et al. 2016)

\section{RESULTS AND DISCUSSION}

\section{Characterisation of ASG and PTC Crude and Fractions Using Raman Spectroscopy}

Raman spectra obtained for raw ASG and PTC, where their different extracts and the fractions acquired between 3500 and $500 \mathrm{~cm}^{-1}$ are depicted, are shown in Figure 4. The Raman spectra of ASG and PTC for raw gum (a), methanol crude extract (MCE) (b) and acetone fraction (AF) (d) are almost identical when compared with the methanol fraction (MF) spectrum (c). The three Raman spectra of the enriched extracts were obtained, and a comparison was made for the effective peaks against that of raw material GA (standard). The spectra of both raw gum samples (ASG and PTC) showed three major peaks at the approximated similar range of 2930, 1354 and $636 \mathrm{~cm}^{-1}$; whereas the spectra of MCE, MF and AF showed the same bands at about 1903 to 1373 $\mathrm{cm}^{-1}$. However, the MF spectrum showed two different bands at 805 and $572 \mathrm{~cm}^{-1}$ (Figure 4). 

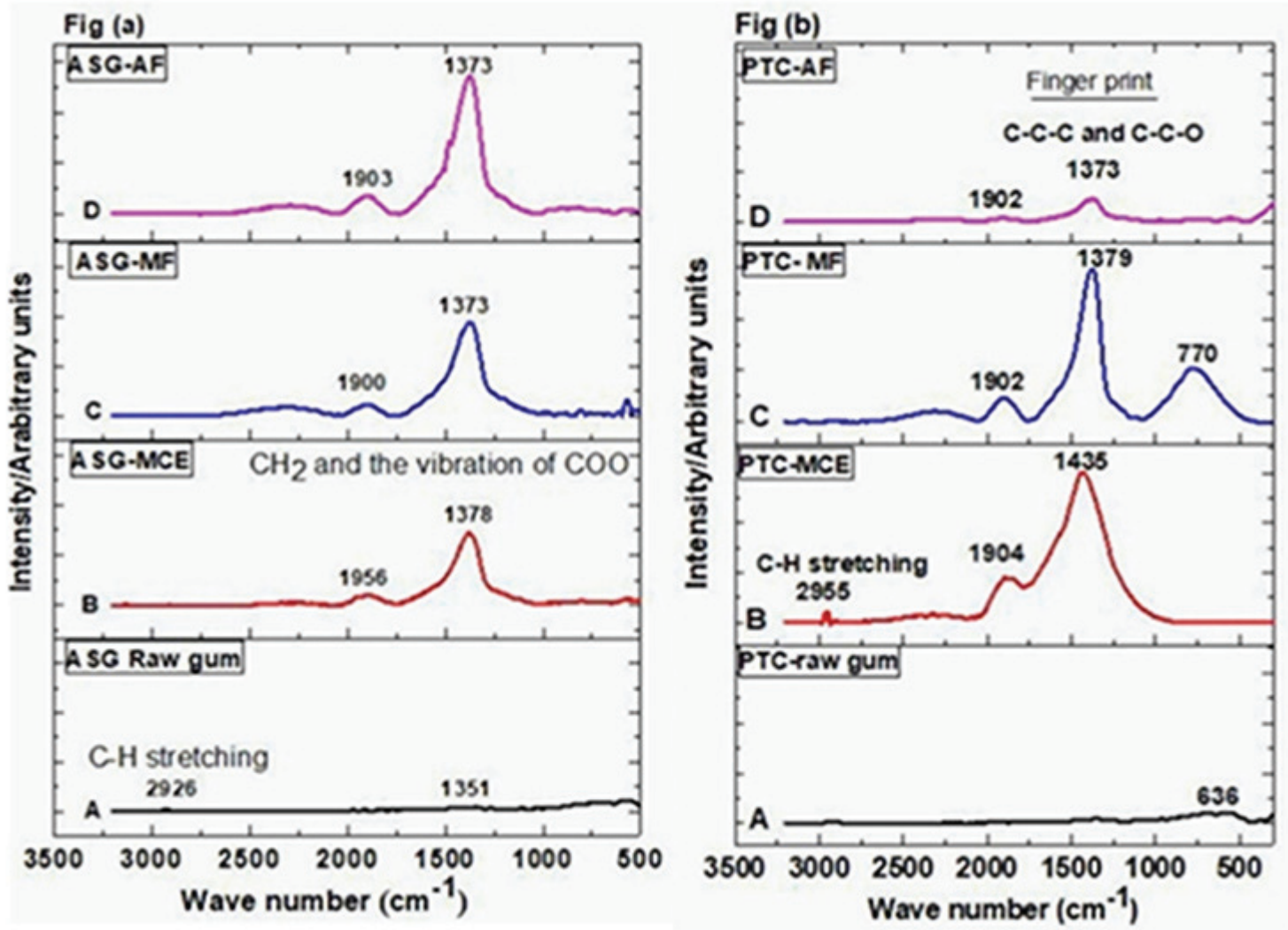

FIGURE 4 The Raman spectra of Acacia seyal gum (ASG) and PTC (A) raw gum, (B) crude extraction, (C) methanol fraction, and (B) acetone fraction, respectively. Figure (4b): Raman spectra of PTC(A), PTC raw gum, (B) PTC crude extraction, (C) PTC methanol fraction, and (D) PTC acetone fraction, respectively.

In this chapter, the spectra characterised by the intense bands were somewhere around $2926 \mathrm{~cm}^{-1}$, which was assigned to the C-H stretching. The results were in agreement with Özbalci et al. (2013), who analysed honey sugar by using Raman spectroscopy. Meanwhile, the band at $572 \mathrm{~cm}^{-1}$ was originated from intense deformation of $\mathrm{C}-\mathrm{C}-\mathrm{C}$ and $\mathrm{C}-\mathrm{C}-\mathrm{O}$, and the sharp band at $1373 \mathrm{~cm}^{-1}$ was assigned to ring deformation. The peak at $1075 \mathrm{~cm}^{-1}$ was assigned mainly to the bending vibration of $\mathrm{C}-\mathrm{H}$ and $\mathrm{C}-\mathrm{O}-\mathrm{H}$ in carbohydrates and to slight contribution by the vibration of the $\mathrm{C}-\mathrm{N}$ bond in proteins and amino acid. The bands around $705 \mathrm{~cm}^{-1}$ were originated to the stretching of $\mathrm{C}-\mathrm{O}$ and $\mathrm{C}-\mathrm{C}-\mathrm{O}$ as well as to the $\mathrm{O}-\mathrm{C}-\mathrm{O}$ bending, whereas the bands in the region of $805 \mathrm{~cm}^{-1}$ were assigned to the $\mathrm{C}-\mathrm{H}, \mathrm{C}-\mathrm{O}-\mathrm{H}$ and $\mathrm{CH}_{2}$ bending (Wiercigroch et al., 2017). A sharp peak at $1266 \mathrm{~cm}^{-1}$ was found to be related to the deformation vibration of $\mathrm{C}-\mathrm{C}-\mathrm{H}, \mathrm{O}-\mathrm{C}-\mathrm{H}$ and $\mathrm{C}-\mathrm{O}-\mathrm{H}$. The absorbance band at $1373 \mathrm{~cm}^{-1}$ was originated from the combination of the bending vibration of $\mathrm{CH}_{2}$ and the vibration of the COO-group, where the same spectral region has been attributed to the flavanol and organic acids; the findings were in agreement with Tahir et al.(2017), who reported rapid prediction of phenolic compounds and antioxidant activity. Based on the results, it is possible to use Raman spectroscopy as a direct and straightforward method of analysis, thus enabling the apiculture and pharmaceutical industries to efficiently assess the antioxidant activity and health benefits from specific bioactive compounds. 
A study was conducted in 2017 by Tahir et al., with the objective of evaluating the phenolic compounds and antioxidant activity of Sudanese honey by using Raman spectroscopy (Tahir et al., 2017). It was demonstrated to be a simple, rapid and nondestructive method to quantify phenolic compounds and antioxidant activities in honey. Another study also reported the effectiveness of Raman spectroscopy for the identification, distribution and quantification of flavonoid aspalathin in green rooibos (Baranska et al. 2006). The results support the spectral data and reference HPLC values; reliable multivariate calibration models were developed for quantification of aspalathin, nothofagin, and the combined dihydrochalcone contents of dried, green rooibos (Baranska et al., 2006).

López-Tobar et al. (2012) have investigated the encapsulation and isomerization of curcumin with cyclodextrins characterised by electronic and vibrational use of Raman spectroscopy. They reported that the structural antioxidant, antitumoral polyphenol curcumin and its complexation with $\mathrm{B}$-and $\mathrm{Y}$-cyclodextrin have a positive impact. Thus, changes may lead to an increase of the chemical stability, the bioavailability and the biological activity of curcumin.

Raman techniques were also used for the identification of bioactive compounds, which included hydroxycinnamic and hydroxybenzoic esters (caffeates, ferulates and gallates) displaying antioxidant and anticancer properties; this was undertaken with particular emphasis on the analysis of the effect of the ring substituents and the nature of the ester alkyl chain on their spectroscopic features (Calheiros et al., 2008).

In this chapter, Raman images of the materials were also generated to ascertain the dispersion of the antioxidant within the hydrocolloid materials such as carotenoids (astaxanthin) and indolic alkaloids. In phenolic compounds such as ferulic acid, p-coumaric acid, caffeic acid and sinapic acid, it was observed that B-carotene was partially agglomerated in certain areas of the film, a fact that could also contribute to enhancing the stability of the bioactive molecule (López-Rubio and Lagaron, 2011).

Moreover, Raman spectroscopy resulted in the identification of carotenoids and indolic alkaloids. As a result, Raman bands at 1520, 1160 and $1005 \mathrm{~cm}^{-1}$ assigned to v1 (C=C), v2 (CC) and $\rho 3\left(\mathrm{C}_{-}-\mathrm{CH}_{3}\right)$ modes, respectively, were attributed to astaxanthin, and the band at 1665 $\mathrm{cm}^{-1}$ could be assigned to the $\mathrm{v}(\mathrm{C}-\mathrm{N}), \mathrm{v}(\mathrm{C}-\mathrm{O})$ and $\mathrm{v}(\mathrm{C}-\mathrm{C})$ coupled mode of the iminoimidazolinone from aplysinopsin (Maia et al., 2014). Thus, the antioxidant activity of the crude extracts may have suggested a possible role for bioactive compounds. Surface-enhanced Raman spectroscopy of phenolic antioxidants provides a systematic evaluation of ferulic acid, p-coumaric acid, caffeic acid and sinapic acid (Aguilar-Hernández et al., 2017) therefore, Raman is considered as an effective tool for bioactive compounds identification.

Three dimensions (3D) of crude and active fraction of ASG and PTC crude methanol and its fractions can be observed (Figure 5): ASG-MCE: crude methanol extraction, ASG-MF: methanol fraction, ASG-AF: acetone fraction, ASG-HF: hexane fraction, and ASG-CHF: chloroform fraction, respectively. Figure (b) shows PTC-MCE: crude methanol extraction, PTC-MF: methanol fraction, PTC-AF: acetone fraction, PTC-HF: hexane fraction, and PTC-CHF: chloroform fraction, respectively. Based on the results, it is possible to use Raman spectroscopy as a direct and straightforward method of analysis, thus enabling the apiculture and pharmaceutical industries to efficiently assess the antioxidant activity and health benefits from certain compounds. 
TABLE 1 Raman Absorptions of Common Functional Group Compared with FTIR

\begin{tabular}{|c|c|c|c|}
\hline Functional Group / Vibration & Region & Raman & InfraRed \\
\hline Lattice vibrations in crystals, LA modes & $10-200 \mathrm{~cm}^{-1}$ & strong & strong \\
\hline$\delta(C C)$ aliphatic chains & $250-400 \mathrm{~cm}^{-1}$ & strong & weak \\
\hline $\mathrm{u}(\mathrm{Se}-\mathrm{Se})$ & $290-330 \mathrm{~cm}^{-1}$ & strong & weak \\
\hline $\mathrm{u}(\mathrm{S}-\mathrm{S})$ & $430-550 \mathrm{~cm}^{-1}$ & strong & weak \\
\hline $\mathrm{u}(\mathrm{Si}-\mathrm{O}-\mathrm{Si})$ & $450-550 \mathrm{~cm}^{-1}$ & strong & weak \\
\hline u (X metal-O) & $150-450 \mathrm{~cm}^{-1}$ & strong & med-weak \\
\hline$u(C-I)$ & $480-660 \mathrm{~cm}^{-1}$ & strong & strong \\
\hline $\mathrm{u}(\mathrm{C}-\mathrm{Br})$ & $500-700 \mathrm{~cm}^{-1}$ & strong & strong \\
\hline $\mathrm{U}(\mathrm{C}-\mathrm{Cl})$ & $550-800 \mathrm{~cm}^{-1}$ & strong & strong \\
\hline $\mathrm{u}(\mathrm{C}-\mathrm{S})$ aliphatic & $630-790 \mathrm{~cm}^{-1}$ & strong & medium \\
\hline $\mathrm{u}(\mathrm{C}-\mathrm{S})$ aromatic & $1080-1100 \mathrm{~cm}^{-1}$ & strong & medium \\
\hline$u(0-0)$ & $845-900 \mathrm{~cm}^{-1}$ & strong & weak \\
\hline$u(C-O-C)$ & $800-970 \mathrm{~cm}^{-1}$ & medium & weak \\
\hline $\mathrm{U}(\mathrm{CC})$ alicyclic, aliphatic chain vibrations & $600-1300 \mathrm{~cm}^{-1}$ & medium & medium \\
\hline $\mathrm{U}(\mathrm{C}=\mathrm{S})$ & $1000-1250 \mathrm{~cm}^{-1}$ & strong & weak \\
\hline \multirow[t]{3}{*}{$\mathrm{u}(\mathrm{CC})$ aromatic ring chain vibrations } & *1580-1600 cm ${ }^{-1}$ & strong & medium \\
\hline & $* 1450-1500 \mathrm{~cm}^{-1}$ & medium & medium \\
\hline & $* 1000 \mathrm{~cm}^{-1}$ & strong/medium & weak \\
\hline$\delta(\mathrm{CH} 3)$ & $1380 \mathrm{~cm}^{-1}$ & medium & strong \\
\hline$\delta(\mathrm{CH} 2) \delta(\mathrm{CH} 3)$ asym & $1400-1470 \mathrm{~cm}^{-1}$ & medium & medium \\
\hline $\mathrm{u}\left(\mathrm{C}-\left(\mathrm{NO}_{2}\right)\right)$ & $1340-1380 \mathrm{~cm}^{-1}$ & strong & medium \\
\hline $\mathrm{u}\left(\mathrm{C}-\left(\mathrm{NO}_{2}\right)\right.$ asym & $1530-1590 \mathrm{~cm}^{-1}$ & medium & strong \\
\hline $\mathrm{U}(\mathrm{N}=\mathrm{N})$ aromatic & $1410-1440 \mathrm{~cm}^{-1}$ & medium & strong \\
\hline $\mathrm{U}(\mathrm{N}=\mathrm{N})$ aliphatic & $1550-1580 \mathrm{~cm}^{-1}$ & medium & strong \\
\hline$\delta\left(\mathrm{H}_{2} \mathrm{O}\right)$ & $\sim 1640 \mathrm{~cm}^{-1}$ & weakbroad & strong \\
\hline $\mathrm{u}(\mathrm{C}=\mathrm{N})$ & $1610-1680 \mathrm{~cm}^{-1}$ & strong & medium \\
\hline $\mathrm{U}(\mathrm{C}=\mathrm{C})$ & $1500-1900 \mathrm{~cm}^{-1}$ & strong & weak \\
\hline$u(C=0)$ & $1680-1820 \mathrm{~cm}^{-1}$ & medium & strong \\
\hline $\mathrm{u}(\mathrm{C} \cong \mathrm{C})$ & $2100-2250 \mathrm{~cm}^{-1}$ & strong & weak \\
\hline $\mathrm{U}(\mathrm{C} \cong N)$ & $2220-2255 \mathrm{~cm}^{-1}$ & medium & strong \\
\hline$U(-S-H)$ & $2550-2600 \mathrm{~cm}^{-1}$ & strong & weak \\
\hline $\mathrm{U}(\mathrm{C}-\mathrm{H})$ & $2800-3000 \mathrm{~cm}^{-1}$ & strong & strong \\
\hline $\mathrm{U}(=(\mathrm{C}-\mathrm{H}))$ & $3000-3100 \mathrm{~cm}^{-1}$ & strong & medium \\
\hline $\mathrm{U}(\cong(\mathrm{C}-\mathrm{H}))$ & $3300 \mathrm{~cm}^{-1}$ & weak & strong \\
\hline $\mathrm{U}(\mathrm{N}-\mathrm{H})$ & $3300-3500 \mathrm{~cm}^{-1}$ & medium & medium \\
\hline $\mathrm{u}(\mathrm{O}-\mathrm{H})$ & $3100-3650 \mathrm{~cm}^{-1}$ & weak & strong \\
\hline
\end{tabular}




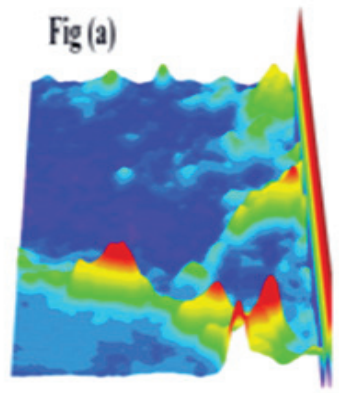

(1ASG- raw gum

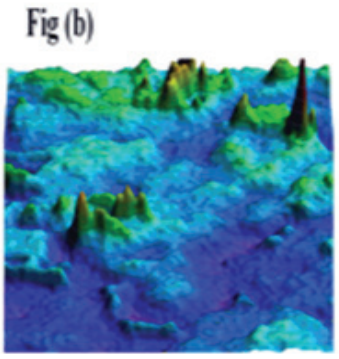

(1) PTC-raw gum

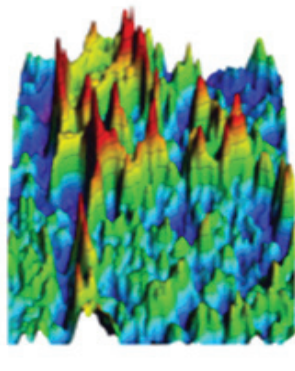

(2) ASG-MCF

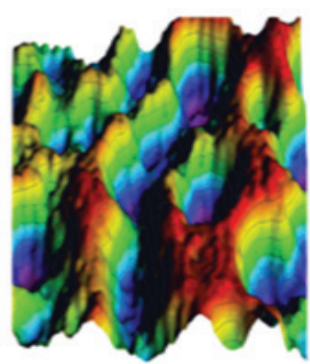

(2) PTC-MCE

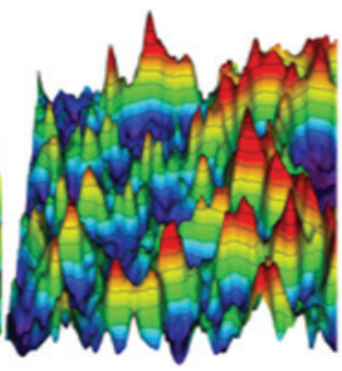

(3) ASG.MF

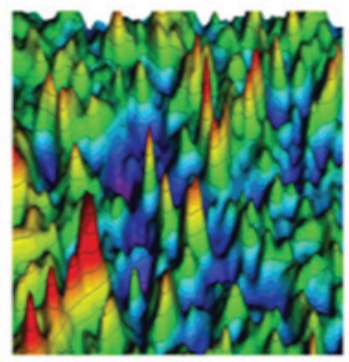

(3) Prebio-T-MF

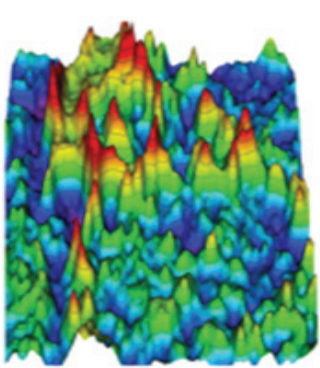

(f) ASGAF

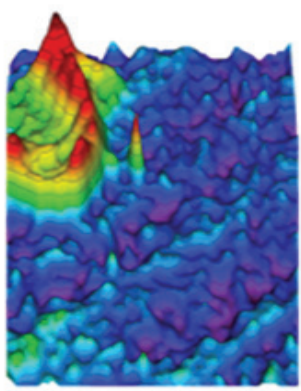

(†) PTC-AF

Figure 5(a) Shows the three dimensional (3D) picture of a crude and active fraction of ASG and PTC methanol and its fractions. ASG-MCE: crude methanol extraction, ASG-MF: methanol fraction, ASG-AF: acetone fraction, ASG-HF: hexane fraction, and ASG-CHF:chloroform fraction, respectively. Figure (b) shows PTC-MCE: crude methanol extraction, PTC-MF: methanol fraction, PTC-AF: acetone fraction, PTC-HF: hexane fraction, and PTCT-CHF:chloroform fraction, respectively.

\section{SUMMARY}

This work can be considered as the first attempt to identify the biological potential of Acacia seyal gum growing in Sudan. Based on the results, it was observed that the methanol-soluble fraction possesses the maximum peaks of the crude extract and the different polarity fractions extracted from the gum. The potential bioactive compounds were displayed by MF and AF, which were secluded from MCE by the Kupchan solvent-solvent partitioning method. Through systematic analyses of Raman spectroscopy towards MCE and its different fractions, it can be learned that the resulted spectra are capable of delivering a large amount of information on macroscopic structures and comprehensive variation rules over the chemical constituents residing in the products. This method can clearly display the differences between the chemical constituents in MCE and their different enriched fractions. The Raman spectra are capable of showing more of the characteristics and features of the ASG samples, as the chemical compositions were concentrated after the extraction of the samples by solvents. The chemical substances in the extracts are somewhat consistent due to the commonality in the extraction methods, with Raman spectroscopy providing a higher repeatability and comparability. Thus, the fact that the Raman spectrum is capable of objectively reflecting the panorama of chemical constituents from a complex system enables this method to be nominated as one of the most credible methods. The outcomes of this study contribute to the 
groundwork of designing future experimentation for a better comprehension on the antioxidative, anticancer and anti-inflammatory effects of the gums. It may as well support future work for discovering the phytochemicals associated with these properties.

\section{ACKNOWLEDGEMENTS}

The authors would like to express their gratitude to the Department of Biotechnology Engineering (BTE), Faculty of Engineering, International Islamic University Malaysia (IIUM) as well as the International Institute for Halal Research and Training (INHART), IIUM, for allowing the authors to use their laboratories and facilities. The authors also extend their thanks to Dr. Elbasheir Sallam for his continuous and unlimited financial support to the Ph.D. candidate conducting this research.

\section{BIBLIOGRAPHY}

Aguilar-Hernández, I., Afseth, N.K., López-Luke, T., Contreras-Torres, F.F., Wold, J.P. and Ornelas-Soto, N. (2017): Surface enhanced Raman spectroscopy of phenolic antioxidants:

A systematic evaluation of ferulic acid, p-coumaric acid, caffeic acid and sinapic acid. Vibrational Spectroscopy, Vol. 89, pp.113-122.

Ali (2003): The effect of treatment with gum Arabic on gentamicin nephrotoxicity in rats: a preliminary study. Renal failure, Vol. 25, No. 1, pp.15-20.

Ali (2010): Effects of Gum Arabic in rats with adenine-induced chronic renal failure. Experimental Biology and Medicine, Vol. 235, No. 3, pp.373-382.

Baranska, M., Schulz, H., Joubert, E. and Manley, M. (2006): In situ flavonoid analysis by FT-Raman spectroscopy: Identification, distribution, and quantification of aspalathin in green rooibos (Aspalathus linearis). Analytical Chemistry, Vol. 78, No. 22, pp.7716-7721.

Calame, W., Weseler, A.R., Viebke, C., Flynn, C. and Siemensma, A.D. (2008): Gum arabic establishes prebiotic functionality in healthy human volunteers in a dose-dependent manner. British Journal of Nutrition, Vol. 100, No. 06, pp.1269-1275.

Calheiros, R., Machado, N., Fiuza, S., Gaspar, A., Garrido, J., Milhazes, N., ... Marques, M. (2008): Antioxidant phenolic esters with potential anticancer activity: a Raman spectroscopy study. Journal of Raman Spectroscopy: An International Journal for Original Work in all Aspects of Raman Spectroscopy, Including Higher Order Processes, and also Brillouin and Rayleigh Scattering, Vol. 39, No. 1, pp.95-107.

Dasgupta, N., and De, B. (2007): Antioxidant activity of some leafy vegetables of India: A comparative study. Food Chemistry, Vol. 101, No. 2, pp.471-474.

El Amin, H.M. (1990): Trees and shrubs of the Sudan: Ithaca press.

Elnour, A., Mirghani, M., Kabbashi, N., Md Alam, Z and Musa, K. (2018): Study of Antioxidant and Anti-Inflammatory Crude Methanol Extract and Fractions of Acacia seyal Gum. American Journal of Pharmacology and Pharmacotherapeutics, Vol. 5, No. 1, p.3

Gill, R. (2014): Modern Analytical Geochemistry: an introduction to quantitative chemical analysis techniques for Earth, environmental and materials scientists: Routledge.

Glover, D.A., Ushida, K., Phillips, A.O. and Riley, S.G. (2009): Acacia (sen) SUPERGUM ${ }^{\text {TM }}$ (Gum Arabic): an evaluation of potential health benefits in human subjects. Food Hydrocolloids, Vol. 23, No. 8, pp.2410-2415.

Görög, S. (2015): Identification in drug quality control and drug research. TrAC Trends in Analytical Chemistry, Vol. 69, pp.114-122. 
Khalid, H., Abdalla, W.E., Abdelgadir, H., Opatz, T. and Efferth, T. (2012): Gems from traditional north-African medicine: medicinal and aromatic plants from Sudan. Natural Products and Bioprospecting, Vol. 2, No. 3, pp.92-103.

Liao, W., Chen, L., Ma, X., Jiao, R., Li, X. and Wang, Y. (2016): Protective effects of kaempferol against reactive oxygen species-induced hemolysis and its antiproliferative activity on human cancer cells. European Journal of Medicinal Chemistry, Vol. 114, pp.24-32. doi:http://dx.doi.org/10.1016/j. ejmech.2016.02.045

López-Rubio, A. and Lagaron, J.M. (2011): Improved incorporation and stabilisation of B-carotene in hydrocolloids using glycerol. Food Chemistry, Vol. 125, No. 3, pp.997-1004.

López-Tobar, E., Blanch, G.P., del Castillo, M.R. and Sánchez-Cortés, S. (2012): Encapsulation and isomerization of curcumin with cyclodextrins characterized by electronic and vibrational spectroscopy. Vibrational Spectroscopy, Vol. 62, pp.292-298.

Luo, H. (2017): Study on the Role of SIRT2 in Stem Cell Aging and Chronic Inflammation. University of California, Berkeley.

Maia, L.F., Ferreira, G.R., Costa, R.C., Lucas, N.C., Teixeira, R.I., Fleury, B.G., ... de Oliveira, L.F. (2014): Raman spectroscopic study of antioxidant pigments from cup corals Tubastraea spp. The Journal of Physical Chemistry A, Vol. 118, No. 19, pp.3429-3437.

Mannino, M.H. (2017): An in vitro investigation of the antioxidant activities of horse myoglobin. Saint Louis University.

Mirghania, M.E., Elnoura, A.A., Kabbashia, N., Alam, M.Z., Musad, K.H., and Abdullahd, A. (2018): Determination of antioxidant activity of gum arabic: An exudation from two different locations.

Mohades, S. (2017): Low Temperature Plasma for the Treatment of Epithelial Cancer Cells.

Musa. (2015): Gum arabic down-regulate PPAR- $\gamma$ and SCD mRNA expression in mice. Polish Annals of Medicine, Vol. 22, No. 1, pp.11-17.

Nasir, O., Wang, K., Föller, M., Bhandaru, M., Sandulache, D., Artunc, F., ... Klingel, K. (2010): Downregulation of angiogenin transcript levels and inhibition of colonic carcinoma by Gum Arabic (Acacia senegal). Nutrition and Cancer, Vol. 62, No. 6, pp.802-810.

Niu, F., Niu, D., Zhang, H., Chang, C., Gu, L., Su, Y. and Yang, Y. (2016): Ovalbumin/gum arabic-stabilized emulsion: Rheology, emulsion characteristics, and Raman spectroscopic study. Food Hydrocolloids, Vol. 52, pp.607-614.

Özbalci, B., Boyaci, İ.H., Topcu, A., Kadılar, C. and Tamer, U. (2013): Rapid analysis of sugars in honey by processing Raman spectrum using chemometric methods and artificial neural networks. Food Chemistry, Vol. 136, No. 3, pp.1444-1452.

Patel, H.A. (2009): Consumar attitude towards processed food products in Gujarat a study on fruits and vegetables processing and spice products.

Phillips (2011a): Biofunctional behaviour and health benefits of a specific Gum Arabic. Food Hydrocolloids, Vol. 25, No. 2, pp.165-169.

Phillips (2011b): An introduction: evolution and finalisation of the regulatory definition of dietary fibre. Food Hydrocolloids, Vol. 25, No. 2, pp.139-143.

Rostron, P., Gaber, S. and Gaber, D. (2016): Raman Spectroscopy, Review. laser, Vol. 21, pp.24.

Sharma, R. (1985): Hypocholesterolemic effect of gum acacia in men. Nutrition Research, Vol. 5, No. 12, pp.1321-1326.

Socrates, G. (2001): Infrared and Raman characteristic group frequencies: tables and charts: John Wiley \& Sons. 
Tahir, H.E., Xiaobo, Z., Zhihua, L., Jiyong, S., Zhai, X., Wang, S. and Mariod, A.A. (2017): Rapid prediction of phenolic compounds and antioxidant activity of Sudanese honey using Raman and Fourier transform infrared (FT-IR) spectroscopy. Food Chemistry, Vol. 226, pp.202-211.

Wang, H., Williams, P.A and Senan, C. (2014): Synthesis, characterization and emulsification properties of dodecenyl succinic anhydride derivatives of gum Arabic. Food Hydrocolloids, Vol. 37, pp.143-148.

Wang, J.Y., Jin, L., Yan, X.G., Sherwin, S., Farrelly, M., Zhang, Y.Y., . . . Zhang, X.D. (2016): Reactive Oxygen Species Dictate the Apoptotic Response of Melanoma Cells to TH588. Journal of Investigative Dermatology, Vol. 136, No. 11, pp.2277-2286. doi:http://dx.doi.org/10.1016/j.jid.2016.06.625

Wiercigroch, E., Szafraniec, E., Czamara, K., Pacia, M.Z., Majzner, K., Kochan, K. ... Malek, K. (2017): Raman and infrared spectroscopy of carbohydrates: A review. Spectrochimica Acta Part A: Molecular and Biomolecular Spectroscopy, Vol. 185, pp.317-335.

Wu, Z., Xu, E., Li, J., Long, J., Jiao, A., Jin, Z. and Xu, X. (2017): Determination of antioxidant capacity of Chinese rice wine and Zhuyeqing Liquor using nanoparticle-based colorimetric methods. Food Analytical Methods, Vol. 10(3), pp.788-798.

Wu, Z., Xu, E., Long, J., Pan, X., Xu, X., Jin, Z. and Jiao, A. (2016): Comparison between ATR-IR, Raman, concatenated ATR-IR and Raman spectroscopy for the determination of total antioxidant capacity and total phenolic content of Chinese rice wine. Food Chemistry, Vol. 194, pp.671-679.

Xin, Lebedkin, S., Besser, H., Pfleging, W., Prinz, S., Wissmann, M. ... Kappes, M.M. (2014): Tailored surface-enhanced Raman nanopillar arrays fabricated by laser-assisted replication for biomolecular detection using organic semiconductor lasers. ACS nano, Vol. 9, No. 1, pp.260-270.

\section{BIOGRAPHIES}

AHMED A.M. ELNOUR was born in Sudan, on 16 November 1978. He graduated from the University Kordofan, El Obeid Sudan, with a Bachelor of Science in Biochemistry and Food Science, B.Sc. degree 1st class (2003). He received the M.Sc in Gum Arabic chemistry from the University of Khartoum, Sudan and the Ph.D. in Biotechnology Engineering from IIU Malaysia, Faculty of Engineering by the title of extraction and identification of bioactive compounds from gum arabic and, its applications for anticancer and anti-inflammatory agents. Currently, he is a Ph.D. research fellow of Biotechnology Engineering at the IIU Malaysia, Gombak, Selangor, where he is presently in charge of the establishment of an advanced center for Bioenvironmental Engineering Research (BERC), Biotechnology Engineering, Faculty of Engineering, IIU Malaysia, and a reviewer in 4 international Journals in UK and Malaysia. Previously a head department of Biochemistry and gum processing at Institute of Gum Arabic \& Desertification Studies, University of Kordofan, Sudan. He is a visiting lecturer of Biochemistry and Molecular biology at Western Kordofan university, faculty of veterinary science, Sudan. He is the author or co-author of numerous publications including; (1) Challenges of Extraction Techniques of Natural Antioxidants and Their Potential Applications Opportunities as Anti-Cancer Agents. Health Sci. J,12(5), 596. DOI: 10.21767/1791-809X.1000596, (2) Determination of the antioxidant activity of gum arabic: An exudation from two different locations. SCIENCEASIA, 44(3), 179-186.doi:DOI:10.2306/ scienceasia1513-1874.2018.44.179, (3) Gum Arabic: An Optimisation of Ultrasonic-assisted extraction of Antioxidant activity. Studia Ubb Chemia, 4(3), 95-116: DOI:10.24193/subbchem.2018.3.08, (4) Study of Antioxidant and Anti-Inflammatory Crude Methanol Extract and Fractions of Acacia seyal Gum. American Journal of Pharmacology \& Pharmacotherapy, 5(1), 3. DOi:10.21767/23938862.100012. (5) Effect of solvent types on phenolics content and antioxidant activities of Acacia polyacantha gum. International Food Research Journal, IFRJ, 24(2017), 369-377. ISSN:1985-4668. He has a several publication and patent under review in high impact factor Journals.

MOHAMED E.S. MIRGHANI completed his first degree in Biochemistry at Cairo University, Egypt then worked as a quality control inspector at the Sudanese Standards \& Metrology Organization 
(SSMO), then he linked to University of Gezira ( $U$ of G) where he conducted MSc in Applied Chemistry and Chemical Technology at the Faculty of Engineering and Technology. He completed his doctorate in food chemistry and biochemistry at University Putra Malaysia (UPM) in 2002. After that he joined the National Oilseed Processing and Research Institute (NOPRI) at U of G, Medani, Sudan, where he directed his research towards the technology of fats and oils in Sudan on conventional and new oilseed production, analysis and uses. Then he joined the Department of Biotechnology Engineering at Faculty (Kulliyyah) of Engineering, (KOE) International Islamic University Malaysia (IIUM). He joint halal research group followed by Halal Research Centre then appointed as a Deputy Director for Research and Innovation at the International Institute for Halal Research and Training (INHART). Dr. Mirghani has many publications on fats and oils technology, analytical techniques, and biodiesel, and also he published many articles on halal and nonhalal detection using advanced analytical techniques. Dr. Mirghani has many collaborations in research at the national and international research groups in Sudan, Malaysia, Canada, KSA and he is a full member of the American Oil Chemists' Society (AOCS) since the year 2000.

MOHAMED Z. ALAM is a Professor and Chair of Bioenvironmental Engineering Research Centre (BERC), Faculty of Engineering at IIUM and was Head of the Department of Biotechnology Engineering from 2009 to 2012. He received his B. Sc. in Chemical Engineering from Bangladesh University of Engineering and Technology (BUET), Bangladesh in 1996. He obtained his M. Sc. in Chemical Engineering from Universiti Kebangsaan Malaysia (UKM) in 1999 and earned a PhD in Biochemical Engineering (Bioenvironmental) from Universiti Putra Malaysia (UPM) in 2002. Professor Alam has 20 years of teaching and research experiences in the field of chemical, biochemical and bioenvironmental engineering especially biofuel, biocatalyst, fermentation technology, waste management and water treatment. Prof. Alam has authored and co-authored some 500 publications including international and local refereed journals and conference proceedings, books, book chapters, patents and technical reports. Having high quality of the journal papers, a large number of citations (about 3000)are being cited every year with high h-index, 31 at Scopus Database.

KHALID H. MUSA he received the B.Sc. degree (with honors) in biochemistry and food sciences from the Faculty of Agriculture, University of Khartoum, Sudan, in 1998. He received M.Sc. and Ph.D. degrees in food science from the National University Malaysia (UKM), Bangi, Selangor, Malaysia, in 2003 and 2010, respectively. In 1998, he joined the Sudanese Standards and Metrology Organization (SSMO), as a food chemist. In 2001 he became a graduate research assistant at UKM till 2010. Since November 2010, he has been with the Food Science Program, Faculty of Science and Technology, UKM. He joined the Department of Food Science and Human Nutrition, Faculty of Agriculture and Veterinary Sciences at Qassim University, Saudi Arabia in 2016. He has published more than 40 scientific papers and chapters in books; his research interests include functional foods, gum arabic, antioxidant, antioxidant sensor, and surimi powder. Dr. Musa is a member of the Nutrition Society of Malaysia (NSM) and the Malaysian Institute of Food Technology (MIFT).

NASRELDIN A. KABBASHI is a Professor and a member of Bioenvironmental Engineering Research Centre (BERC), Faculty of Engineering at IIUM and a staff at the Department of Biotechnology Engineering. He obtained his BsC from Gezira University- Sudan 1989, M. Sc. in Chemical \& Environmental Engineering from Universiti Putra Malaysia (UKM) in 1998 and earned a PhD in Chemical \& environmental Engineering from Universiti Putra Malaysia (UPM) in 2002. Highly qualified senior professional Engineering professor with proficiencies in managing start-up project and team, and sector planning spearheading operations based on service excellence model, best practices, benchmarks; having 17+ years of diversified experience in Ruler Development planning, studies and project in Chemical engineering implementation, portfolio management, bioremediation, climate change effect, proven experience in collaborating with senior management in enhancing research collaborations with different disciplines, consultants based on market need; excellent ability in implementing strategic plans for enhancing the institute vision, mission and objectives and other institute trends. Having high quality of the journal papers, a large number of citations are being cited every year with high h-index, at Scopus Database. 